\title{
Parameter Studies on the Ultimate Bearing Capacity of Tube-Gusset Joints
}

\author{
Wei Qing $\mathrm{Li}^{1, \mathrm{a}^{*}}$, Shu Xia Yan ${ }^{1, \mathrm{~b}}$ \\ ${ }^{1}$ School of Civil Engineering and Architecture, Changzhou Institute of Technology, Changzhou \\ China. \\ agouni@zju.edu.cn, b2494987865@qq.com
}

Keywords: transmission tower; tube-gusset; joint; bearing capacity

Abstract. A parameter study is carried out to investigate the influence of various factors. The axial force, the width of the stiffening ring, the height of the ring, the diameter of the tube, the wall thickness, the length and the thickness of the joint are considered. At present, the ultimate bearing capacity formulas of the gusset-tube joints established by various countries are based on the failure mode of over plastic deformation in the compression region of the main tube wall. The analysis of the parameters of this kind of joints shows that the specimens failed due to excessive plastic deformation in the tension region are of $34.34 \%$ of the $81 \mathrm{FE}$ specimens.

\section{Introduction}

Tube-gusset joint mainly consists of a chord tube, two branch tubes, a gusset plate and two ring stiffeners. The branch tubes are connected to the chord tube through the gusset plate, and the gusset plate and the chord are welded together. The failure of the joints often leads to the failure of the branch tubes, which leads to the final damage of the whole structure. These kinds of joints which integrate all components with a gusset plate make force transmission way clear. At present, most of the steel tubular joints are analyzed by methods of finite element analysis and by the methods of the stress concentration factor [1-4]. According to the existing national standards, the calculation results are too conservative, which makes the engineers can not accurately grasp the safety factor of the structure[5,6], and it will have a negative impact on the economy of the construction. At the current time, there is no effective method to estimate the local buckling of the tube wall and the difference between the stiffening and the unstiffening[7]. And the reference values given by the empirical formula of foreign countries can not reflect the performance of the joints under various load conditions[8].

\section{Finite element model}

Fig. 1 shows the Mechanical model and the Finite element model of the ring stiffened gusset-tube joints. In the numerical analysis of the joints, in order to better analyze the stress distribution 8 nodes (each node with three degrees of freedom) hexahedral solid elements Solid 185 is used. The constraints and loads of the FEA specimens are applied according to the actual conditions. For the steel tubular tower joint, one end of the main tube is considered as the fixed bearing, and the other end is the directional support with the axial displacement of the main tube. Q345 steel, elastic modulus and Poisson's ratio of 0.3 are used in this paper. The elastic-plastic development of the material is determined by the von Mises yield criterion [7].

Parameters mainly include: elastic modulus, Poisson ratio and yield strength. In this paper, Poisson ratio $=0.3$, elastic modulus $\mathrm{E}=2.06 \mathrm{e} 10^{5} \mathrm{~N} / \mathrm{mm}^{2}$, and yield strength is $345 \mathrm{Mpa}$. A Newton-Raphson iteration method is used. Through finite element analysis, it can be found that parameters affecting the

bearing capacity of the tube-gusset joint mainly include: steel tube diameter $\mathrm{D}$, thickness of the tube $\mathrm{t}$, gusset length $\mathrm{B}$, gusset thickness $t_{g}$ and the angle of ring stiffener $\lambda$. In addition, base on the actual stress state, 
the axial force on the tube as an important influential factor were analyzed. For convenience of analysis, dimensionless form of parameters is adopted, and the dimensionless parameters include: $\alpha, \beta, \gamma, \eta$. Its definition is respectively: $\alpha=\mathrm{D} / \mathrm{t}, \beta=\mathrm{B} / \mathrm{D}, \gamma=t_{g} / \mathrm{t}$ and $\eta=\sigma / \sigma_{y}$. The thickness of the ring stiffeners is $10 \mathrm{~mm}$. The angles of ring stiffeners take 3 levels, respectively in 45 degrees, 60 and 90degrees.

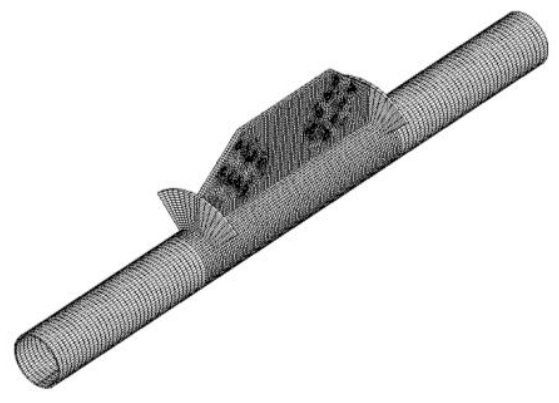

Fig. 1. Finite element model.

The chord tube is $2500 \mathrm{~mm}$ in length and $200 \mathrm{~mm}$ in diameter. The distance between the end of the tube and the gusset plate is set to be at least 3 times the diameter of the tube in order to eliminate the influence of the loading conditions on the end of the tube, while the axial force is set to be zero. the angle between the chord tube and Branch tubes in tension or compression is 45 degrees. According to the above geometric parameters, a total of 81 finite element models are established to analyze the nonlinear properties of the tube-gusset joints.

\section{Parameter study}

Effects of $\alpha$

FromFig. 2 we can see that the influences of $\alpha$ to the moment-rotation relationships are very obvious. The initial bending stiffness of the joint is increased with the increase of the wall thickness.

This is because when the wall thickness is increased, the radial stiffness increases and the deformation decreases, so the initial bending stiffness of the joint is also increased.
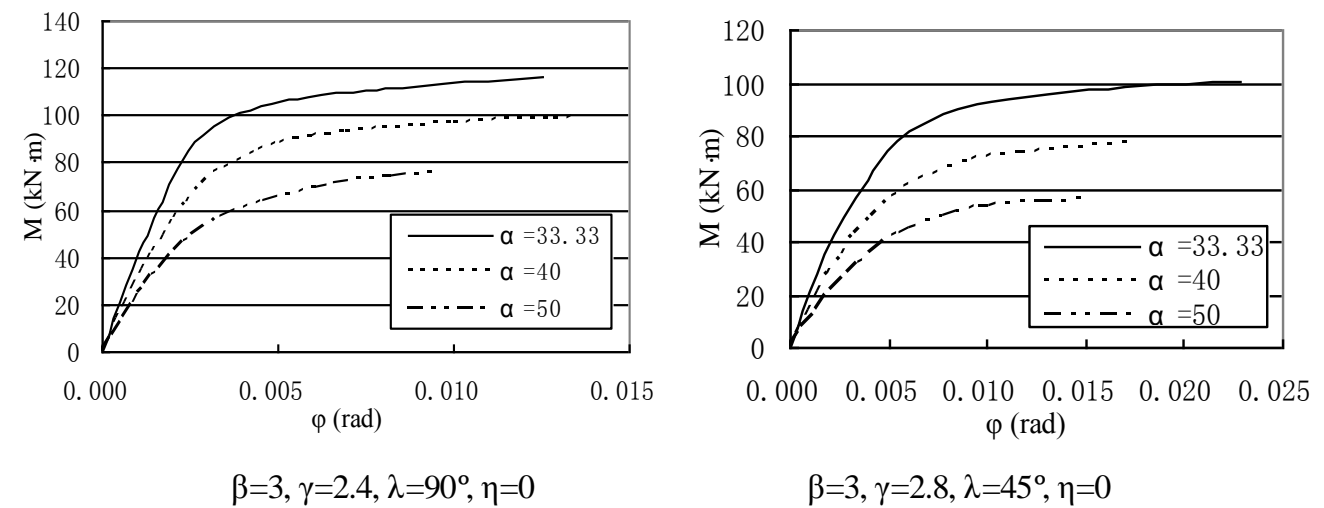

Fig. 2. $M-\varphi$ curves of various $\alpha$

Effects of $\beta$

With the increase of the length of the joint, the bearing capacity can be improved increasingly. Because the longer the intersection of the gusset plate and the tube, the more the stiffness. When the stress distribution is more uniform, the stress concentration decreases relatively. Researches shows that there is a reasonable range the gusset plate length [7]. This is mainly because the ultimate load carrying capacity of the joints is mainly controlled by plastic deformation of the boundary area of the joint, and has little relation with the length 
of the gusset. Therefore, in the design of $\mathrm{K}$ type tube-gusset joints the effective width of the gusset plate should be considered.
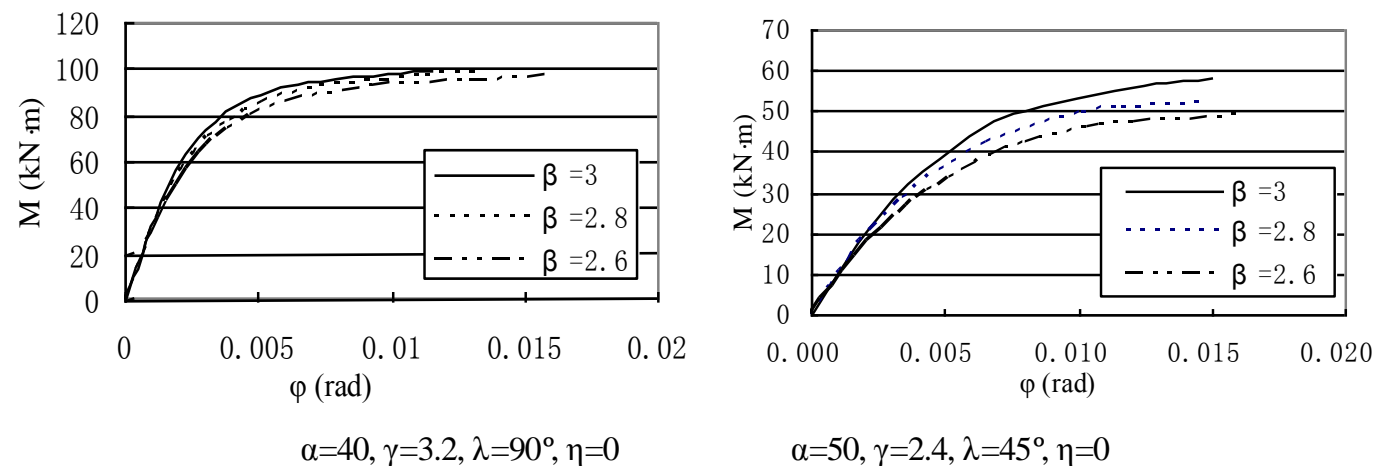

Fig. 3. $M-\varphi$ curves various $\beta$

Effects of $\gamma$
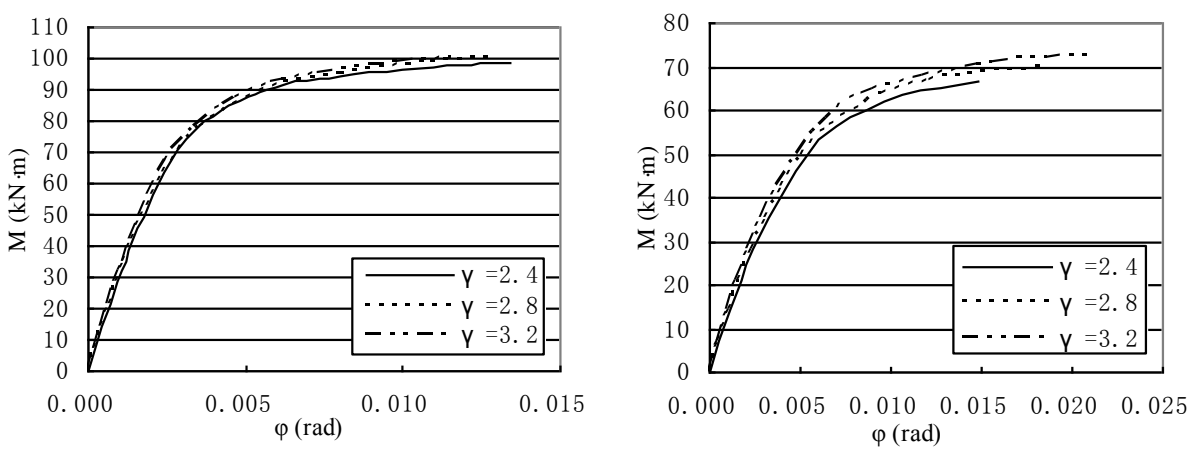

$$
\alpha=40, \beta=3, \lambda=90^{\circ}, \eta=0 \quad \alpha=40, \beta=2.6, \lambda=45^{\circ}, \eta=0
$$

Fig. 4. $M-\varphi$ curves various $\gamma$

By Fig. 4, the effect of $\gamma$ on the moment rotation curve is very small. the ultimate strength of the joints increases with the increase of the thickness of the gusset plate and the thickness of the wall. The initial bending stiffness of joint also increases slightly.

Effects of $\lambda$

FromFig. 5 it is known that the influence of $\lambda$ to the curve is very obvious, and the initial bending stiffness of the joints increases with the increase of the width of the ring stiffeners.
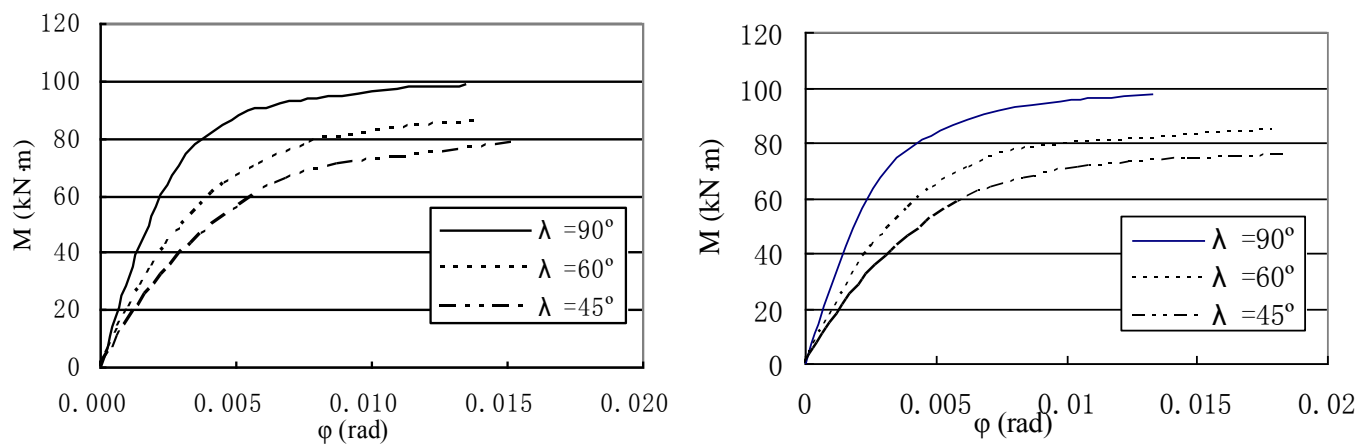

$\alpha=40, \beta=3, \gamma=2.4, \eta=0 \quad \alpha=40, \beta=2.8, \gamma=3.2, \eta=0$

Fig. 5. $M-\varphi$ curves various $\lambda$ 


\section{Effects of $\eta$}

We can see from Fig. 6, the influences of $\eta$ to the moment-rotation relationships are very obvious. The bearing capacity of the joint decreases with the increase of the axial forces. But the influence of $\eta$ to the initial bending stiffness of the joints is very small.
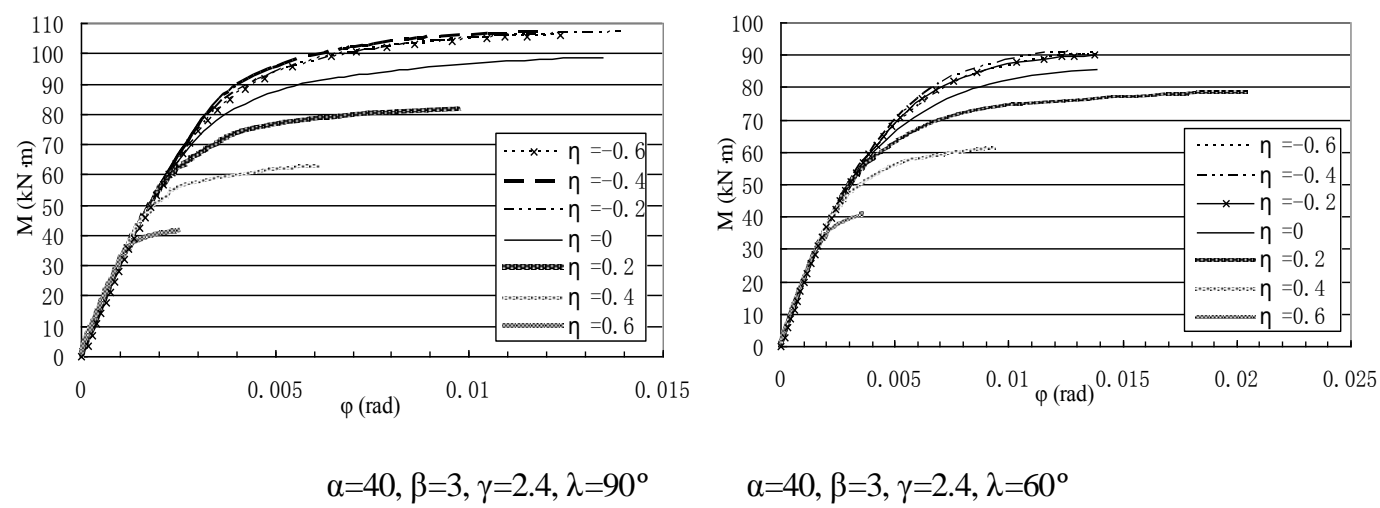

Fig. 6. $M-\varphi$ curves various $\eta$

\section{Summary}

The influences of various parameters on the ultimate bearing capacity of the tube-gusset joints are studied by the finite element analysis.

The axial load has a great influence on the ultimate bearing capacity of the joints. The increase of the ratio of the diameter and wall thickness of the $\mathrm{D} / \mathrm{t}$ will lead to the decrease of the ultimate bearing capacity of the joint. The bearing capacity of the joint is increased with the increase of the length of the joint, while the thickness of the gusset plate has a very small influence. The ring stiffeners can effectively improve the ultimate bearing capacity of the joints, and reduce the plastic deformation of the tube wall.

\section{Acknowledgements}

This research project was supported by the scientific research project of Ministry of Housing and Urban-rural (project number: 2013-K2-23).

\section{References}

[1] Kosteski N,Packer J A.Experimental examination of branch plate-to-RHS member connection types.In:Puthli R,Herion S,eds.Proceedings of the Ninth International Symposium on Tubular Structures. Dusseldorf: 2001.135-144.

[2] Cao J J,Packer J A,Kosteski N.Experimental study of connections between longitudinal plates and RHS columns.In:Choo Y S, van der Vegte G J,eds[J]. Proceedings of the Eighth

[3] Chan T K,Soh C K,Fung T C.Experimental study of a full-scale multiplanar tubular XT-joint. In:Choo Y S, van der Vegte G J,eds.Proceedings of the Eighth International Symposium on Tubular Structures. Singapore:1998.131-138.

[4] Marshall P W.Designing tubular connections with AWS D1.1.Welding [J]. Journal. 1989, 68(3):45-52.

[5] Choo Y S, Qian X D, Liew J Y R, Wardenier J. Static strength of thick-walled CHS X-joints-part I. New approach in strength definition. Journal of Constructional Steel Research. 2003, 59: 1201-1228

[6] Scola S,Redwood R G, Mitri H S. Behaviour of axially loaded tubular V-joints[J]. Journal of Constructional Steel Research. 1990, 16:89-109. 
[7] Packer JA, Henderson JE. Design guide for hollow structural section connections[S]. Canadian Inst Steel. [8] Wang B,Hu N,Kurobane $\mathrm{Y}$ et al.Damage criterion and safety assessment approach to Tubular joints. Engineering Structures. 2000, 22:424-434. 